Check for updates

Cite this: RSC Adv., 2019, 9, 37474

Received 9th October 2019

Accepted 4th November 2019

DOI: 10.1039/c9ra08231j

rsc.li/rsc-advances

\section{Alchemilla vulgaris agg. (Lady's mantle) from central Balkan: antioxidant, anticancer and enzyme inhibition properties}

\author{
Sanja Vlaisavljević, (DD *a Sanja Jelača, ${ }^{\text {b }}$ Gökhan Zengin, ${ }^{c}$ Neda Mimica-Dukić, ${ }^{a}$ \\ Sanja Berežni, ${ }^{a}$ Milorad Miljića and Zora Dajić Stevanovićd
}

The current study was designed to evaluate the phytochemical profile and biological properties (antioxidant, enzyme inhibitory and cytotoxic activity) of methanolic, ethanolic, ethyl-acetate and water extracts of Alchemilla vulgaris from Southeast Serbia (central Balkan) which was traditionally used to alleviate and treat many diseases. Bioactive compounds were characterized by LC-MS/MS technique and biological properties were evaluated using antioxidant, enzyme inhibitory and cytotoxic assays. Twentysix phenolic compounds were quantified in methanolic, ethanolic, ethyl acetate and water extracts, whereas the highest yields were found in ethyl-acetate (EA) extract (gallic acid, caffeic acid, catchin, quercetin). This extract has also shown the greatest antioxidant, anticancer and inhibitory enzyme activities which were demonstrated for the first time in this study. The obtained results indicated that Alchemilla vulgaris from South Serbia possesses high potential for pharmaceutical applications.

\section{Introduction}

Nature has been an inexhaustible source of bioactive compounds which have been used since ancient times for treatment of many diseases. Today more interest is being paid to understanding the complex role of plant nutrition where medical plants have particular importance. These plants include various types of plants for medicinal purposes. They are considered as a rich source of bioactive ingredients. Serbia is one of the world's most biodiverse centers, rich in medical plants, where some of them have not been determinated yet or there is no information on their ingredients and bioactivity. ${ }^{13}$

Alchemilla vulgaris, an aggregate species, commonly known as Lady's mantle or lion's foot, is a perennial herbaceous plant belonging to the rose family (Rosaceae).

The status of the species Alchemilla vulgaris is still not completely resolved and there are a few opinions. However, most of them treat the taxon as an aggregate of microspecies, which were also considered as subspecies or varieties of the species.

\footnotetext{
${ }^{a}$ Department of Chemistry, Biochemistry and Environmental Protection, Faculty of Sciences, University of Novi Sad, Trg Dositeja Obradovića 3, 21000 Novi Sad, Serbia. E-mail: sanja.vlaisavljevic@dh.uns.ac.rs; Fax: +381 21454065; Tel: +381 214852770

${ }^{b}$ Department of Immunology, Institute for Biological Research "Siniša Stanković, University of Belgrade, Serbia

${ }^{c}$ Department of Biology, Science Faculty, Selcuk University, Konya, Turkey

${ }^{d}$ Faculty of Agriculture, University of Belgrade, Serbia
}

According to Flora of Serbia (Genus Alchemilla, Gajić, 1972) name of the species - Alchemilla vulgaris L. is valid; the species is present in Serbia with three subspecies (subsp. montana, subsp. pratensis and subsp. vulgaris). ${ }^{\mathbf{1 5}}$

Among ethnobotanical reports on Alchemilla vulgaris for Southeast Europe and the territory of Balkan peninsula, it is to mention a comprehenisve work of Tucakov (1997), and his reports on adstringent and antidiarrheal, as well as effects against pruritus vulvae, bleeding from uterus and menstrual pains. The most used folk names according to Simonovic (1959) are: "virak", "vrkuta", "rosanica”, "biserak", "virkovina”, "virić" and "gospinplašt" (it is interesting that the latter literally means Lady's mantle). ${ }^{12,13}$

It is 30 to $50 \mathrm{~cm}$ long half-rosette herbaceous plant with corrugated and lobed kidney-shaped to semicircular leaves and the yellowish-green flowers form clusters. The plant blooms from June through to September and can be found on roadsides, grasslands bank, and mountain slopes.

Aerial parts of the plant are often used against gastrointestinal diseases and inflammatory processes, as well as for improvement wound healing due to its strong antimicrobial and anti-inflammatory effects. ${ }^{1}$ The plant is very popular especially due to its great effect against women's problems and diseases such as fibroids, cysts, endometriosis, infertility, relief of menstrual problems and regulation of the menstrual cycle and reproductive and thyroid hormones balancing. ${ }^{2}$ Extract of the plant exhibits high scavenge potential, especially towards superoxide anion radical. The results obtained in some studies indicate that presence of some phenolics, especially tannins, may contribute to the antioxidant activity. ${ }^{3,4}$ Furthermore, Takir 
et al. (2015) demonstrated that methanolic extract of Alchemilla vulgaris has shown vasorelaxant and hypotensive effects. ${ }^{5}$

The extracts of leaves and roots of Alchemilla vulgaris have been reported to inhibit the orthopox viruses in Vero cell lines. ${ }^{6}$ Bahadir et al., 2017 have performed in their study that extracts of Alchemilla vulgaris demonstrated a hepatoprotective activity increasing the aminotransferase (ALT) level in carbon tetrachloride induced mice serum. ${ }^{7}$

In the Southeast Europe and the Balkan peninsula, the Lady's mantle is very popular and acknowledged medicinal plant, which is traditionally used in folk medicine and in range of herbal remedies. The herb is mostly used for preventing of woman illnesses, such as menstrual problems, the oligomenorhea and dysmenorrheal, the menopausal complaints, for regulation of vaginal secretion, polycystic ovaries and even for infertility. ${ }^{8-10}$ Moreover, the Lady's mantle is used as diuretic, anti-anemic and anti-diabetic, for wounds and ulcers, hernias and muscle atrophy, ${ }^{11}$ and it is readily used for wound healing, especially when used externally for ulcers, eczema and skin. There are also notes on use for mild and nonspecific diarrhea and for slow metabolism. ${ }^{12}$ As reported for other regions, the most records refers to woman illnesses and disorders uses, in addition to astringent, antihemorrhagic, tonic, cardiotonic and diuretic effects. ${ }^{11}$ In general, there are not many reports on detailed phytochemical profile of Alchemilla and related biological properties, especially focusing on anticancer properties and in particular of the estrogen depended cancer lines. The current study focuses on phytochemical composition assessment, targeting the phenolic compounds, in different extracts of Alchemilla vulgaris collected from the central Balkan (Southeast Serbia) region. The chosen populations originated from sites where the plant material is collected from the wild for Serbian and regional market needs. The main goal of the present study was to verify the existing ethnobotanical data by performing several antioxidant activity tests, as well as the anticancer and enzyme activity analyses. Evaluation of antioxidant capacity has been also performed using different tests such as 2,2-diphenyl-1-picrylhydrazyl (DPPH), 2,2'-azinobis-(3ethylbenzothiazoline-6-sulfonic acid (ABTS), Cupric Reducing Antioxidant Capacity (CUPRAC), phosphomolibdenum, metal chelating and Ferric Reducing Antioxidant Power (FRAP). Concerning already known health beneficial effects of the plant, in first uses for gynecological disorders 8, we decided to perform investigation on anticancer activity of plant extracts on cancer cells obtained from reproductive tissues, such as human breast aidenocarcinoma (MCF7 cell line), cervical adenocarcinoma (HeLa) and ovarian carcinoma (A2780) in addition to prostate adenocarcinoma (PC-3 cell line). The efficacy of different Alchemilla vulgaris extracts against cancer cell lines was evaluated using two viability tests, MTT based on the measurement of mitochondrial respiration and crystal violet (CV), on the number of adherent cells in culture that retained after the treatment.

There are also reports which have shown that plants from Alchemilla genus were traditionally used for skin and neurodegenerative disorders and against diabetes and gastrointestinal problems of this plant, ${ }^{14-17}$ its ability to inhibit anti- cholinesterase, ${ }^{41}$ anti-tyrosinase and anti-amylase activity of $A$. vulgaris extracts will be investigated in this study.

These investigations were performed to verify whether there are some other biological performances of Lady's mantle extracts which have been neglected so far, as there is not such ethnopharmacological information.

For best of our knowledge, the evaluation of Lady's mantle anticancer activity, especially on estrogen depended tumors, is reported for the first time. Summarily, the phytochemical characterization in relation to antioxidant activity, enzyme inhibitory effects and anticancer activity of different Alchemilla vulgaris extracts are presented to clarify already known ethnopharmacological records, as well as to identify some novel possible biological effects of the plant.

\section{Material and methods}

\section{Plant material}

Plant material was collected at the flowering stage in midsummer 2017, from the site situated in south Serbia, the Vlasina lake (E 22.36446000 N 42.73636300, $1234 \mathrm{~m}$ above sea level). The habitat of the population is wet grassland of the Calthion type. Plant vouchers were deposited at Herbarium of Applied Botany Department of the Faculty of Agriculture, University of Belgrade, under voucher code 85000 BEO. The collected material was air dried.

\section{Extracts preparation}

Dry plant material was macerated for $24 \mathrm{~h}$ in $80 \%$ methanol ( $\mathrm{v} /$ v), $70 \%$ ethanol $(\mathrm{v} / \mathrm{v}), 70 \%$ ethylacetate $(\mathrm{v} / \mathrm{v})$ and distilled water $\left(\mathrm{dH}_{2} \mathrm{O}\right)$ at room temperature using incubator shaker and filtrated (IKA $\AA)$. The supernatants were taken for drying. The obtained residues were dissolved in dimethyl sulfoxide (DMSO) to the concentration of $10 \mathrm{mg} \mathrm{mL}^{-1}$. The extracts (methanolic$\mathrm{MeOH}$, ethanolic-EtOH, ethylacetate-EA, water- $\mathrm{H}_{2} \mathrm{O}$ ) were stored in dark at $+4{ }^{\circ} \mathrm{C}$ until further analyses.

\section{Quantification of bioactive compounds using liquid chromatography tandem-mass spectrometry (LC-MS/MS) technique}

Determination of 45 selected phenolic compounds was performed according to previously described method. ${ }^{18}$

Data were acquired in dynamic multiple reaction monitoring (MRM) mode, using the optimized compound-specific parameters. For all the compounds, peak areas were determined using Agilent Mass Hunter Workstation software - Qualitative Analysis (ver. B.03.01.). Calibration curves were plotted and samples' concentrations calculated using the OriginLabs Origin Pro (ver. 9.0) software.

\section{Assessment of antioxidant activity and total content of phenolic compound}

DPPH assay. Colorimetric DPPH radical scavenging activity was measured according to the method described by Espin et al., $2000 .{ }^{19}$ The obtained results were expressed as milligrams 
of Trolox equivalents per gram of dry weight (mg TE per g d.w.), calculated according to the Trolox standard calibration curve.

ABTS assay. The ABTS radical scavenging ability was determined according to the method reported by Re et al. (1999). The results were evaluated as Trolox equivalents per gram of dry weight (mg TE per $g$ d.w.).

CUPRAC assay. The cupric reducing power ability was detected by CUPRAC assays as reported by Apak et al. (2006). ${ }^{60}$ The results were expressed as Trolox equivalents per gram of dry weight (mg TE per $\mathrm{g}$ extract d.w.).

Phosphomolybdenum assay. The phosphomolybdenum assay was performed according to the method reported by Prieto et al. (1999). ${ }^{20}$ The results were evaluated as Trolox equivalents per gram of dry weight (mmol TE per $g$ d.w.).

Metal chelating. Ferrozine assay was performed to detect the metal chelating ability as reported by Dinis et al. (1994) ${ }^{61}$ The results were provided as ethylenediaminetetraacetic acid (EDTA) equivalent (mg EDTAE/g extract).

FRAP assay. The FRAP assay was conducted according to Benzie and Strain (1996), adapted for 96 well plate. The results were expressed as $\mathrm{mg}$ of ascorbic acid equivalents per $\mathrm{g}$ of dry weight (mg AAE per $\mathrm{g}$ d.w.) using the calibration curve of ascorbic acid. ${ }^{22}$

Each antioxidant assay was carried out in triplicate and results were expressed as mean values.

TPC assay. Total phenolic compounds were determined with Folin-Ciolcateu reagent using the method of Medina-Remon et al. (2009). ${ }^{23}$ The results were expressed as milligrams of gallic acid equivalents per $\mathrm{g}$ dry weight (mg GAE per $\mathrm{g}$ d.w.) using standard calibration curve of gallic acid.

\section{Enzyme inhibitory activity}

The extracts were tested as sources of several enzyme inhibitors, including $\alpha$-amylase, cholinesterases (AChE and BChE), and tyrosinase. The procedures of these assays were reported in our earlier work. ${ }^{23-27}$ The enzyme inhibitor effects were evaluated as equivalents of acarbose for $\alpha$-amylase, galantamine for acetyl cholinesterase (AChE) and butyryl cholinesterase (BChE), and kojic acid (KAE) for tyrosinase.

\section{Reagents and cells}

Culture medium RPMI-1640 and Dulbecco's Modified Eagle Medium (DMEM) were purchased from Biowest (MO, USA). Dimethyl sulfoxide (DMSO), phosphate-buffered saline (PBS), fetal calf serum (FCS) were acquired from Sigma (St. Louis, MO, USA).3-(4,5-dimethythiazol-2-yl)-2,5-diphenyltetrazolium

bromide (MTT) was bought from Applichem (MO, USA) while crystal violet was obtained from Mol (Belgrade, Serbia). The Penicillin Streptomycin solutionsolution was bought from Biological Industries (Cromwell, CT, USA). MCF7(breast adenocarcinoma), HeLa (cervical adenocarcinoma) and PC-3 prostate (adenocarcinoma) cell lines were obtained from American Type Culture Collection (Rockville, MD, USA) while the A2780 (ovarian carcinoma) cells were from European Collection of Authenticated Cell Cultures (Salisbury, UK). Cell lines MCF7 and PC-3 were routinely cultivated in HEPES-buffered RPMI-
1640 medium while HeLa and A2780 cells were cultivated in DMEM. Both mediums were supplemented with $10 \%$ heatinactivated FCS, $2 \mathrm{mM}$ L-glutamine, $0.01 \%$ sodium pyruvate, penicillin (100 units per $\mathrm{mL}$ ) and streptomycin $\left(100 \mu \mathrm{g} \mathrm{mL}{ }^{-1}\right)$ and cells were maintained at $37^{\circ} \mathrm{C}$ in a humidified atmosphere with $5 \% \mathrm{CO}_{2}$. For viability screening MCF7 and HeLa cells were seeded at $2 \times 10^{3}$ cells per well, PC- 3 cells at $5 \times 10^{3}$ cells per well and A2780 in at $3 \times 10^{3}$ cells per well overnight and then treated with a wide range of concentration of $A$. vulgaris extracts for $72 \mathrm{~h}$. Peritoneal exudates cells were collected from the peritoneal cavity of C57BL/6 mice by rinsing with ice-cold PBS. Mice were originated from the facility at the Institute for Biological Research "Siniša Stanković" (IBISS), University of Belgrade (Belgrade, Serbia). Cells were washed with PBS, seeded at $1.5 \times 10^{5}$ cells per well in 96-well plates and allowed to adhere overnight. Before treatment, non-adherent cells were removed and cells were then exposed to the same concentration range of isolated extracts.

\section{Determination of cell viability by mitochondrial dehydrogenase (MTT) and crystal violet (CV) assays}

The activity of mitochondrial dehydrogenase was defined by a reduction of MTT (3-(4,5-dimethylthiazol-2-yl)-2,5diphenyltetrazolium bromide) to formazan. Cells were seeded overnight and treated with experimental compounds for 72 hours. Afterward, cells were cultivated in the presence of $0.5 \mathrm{mg}$ $\mathrm{mL}^{-1}$ MTT (Sigma, St Louis, MO, USA) from $30 \mathrm{~min} 1 \mathrm{~h}$. Thereafter, the medium was discarded and cells were lysed in DMSO. The conversion of MTT to formazan by metabolically viable cells was measured at $540 \mathrm{~nm}$ and cell viability was calculated as a percentage of control, untreated cells.

For CV test, cells were fixed with $4 \%$ of paraformaldehyde (PFA) and stained with $1 \% \mathrm{CV}$ solution for $15 \mathrm{~min}$ at RT. Afterward, cells were washed and dried. Dye was dissolved in acetic acid and the absorbance was measured at $540 \mathrm{~nm}$.

\section{Statistical analysis}

For data analysis, the Statistica 12 software was used. To analyze the significance of the differences between applied treatments the analysis of variance (ANOVA), followed by the StudentNewman-Keuls test was used. A $p$ value less than 0.05 were considered significant.

\section{Results and discussion}

\section{LC-MS/MS characterization of phenolic compounds}

It is well-known that the flavonoids and their glycosides are responsible for antioxidant, anticancer, and cardioprotective activity.$^{28}$ LC-MS/MS analysis was carried out to get insight into polyphenolic profile of $A$. vulgaris extracts and results are presented in the Table 1 . The study showed variations in the amounts of phenolic compounds among the investigated extracts. The obtained results have shown clearly that EA extract was the richest in phenolic compounds. On the other hand, the number of quantified phenols and their amounts was notable lower than in the water extract. Phenolic acids, mainly the gallic 
Table 1 The concentrations of selected phenols in Alchemilla vulgaris extracts obtained by LC-MS/MS

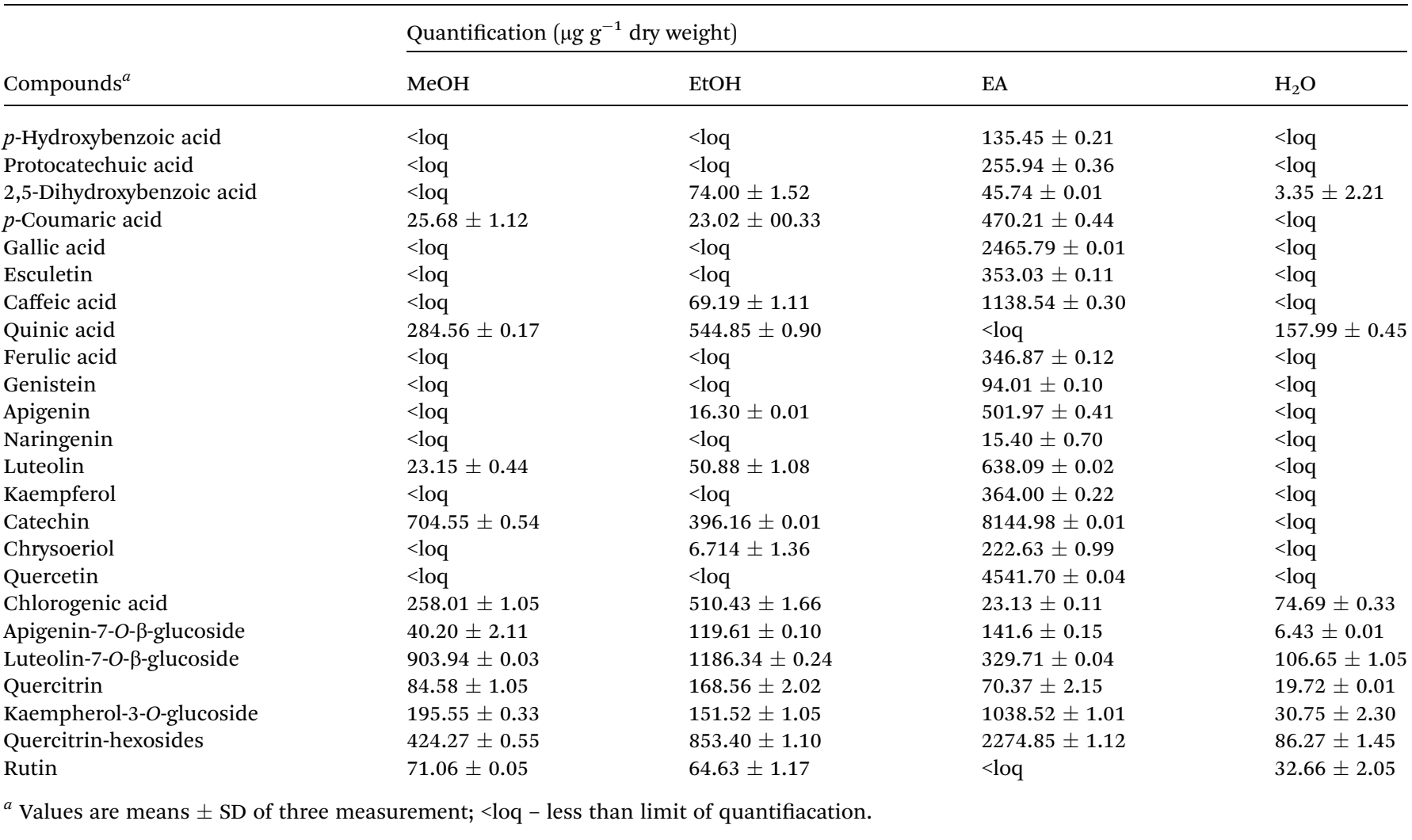

and caffeic acids were the most presented and recorded for EA extract only. Generally, the amount of gallic and caffeic acids was about ten times higher comparing with the other phenolic acids in all tested extracts. Also, we can notice that chlorogenic acid was quantified in the highest amount in EtOH extract but in a lowest amount in EA extract. The health-benefits of this phenol acid is correlated to several health benefits including antioxidant, anticancer, antimutagenic, anti-diabetic effects. ${ }^{29,30}$ Duckstein et al. ${ }^{31}$ have detected in Alchemilla vulgaris extracts a significant concentration of phenolic acids, such as chlorogenic, gallic, ellagic acids in lower concentrations.

Besides phenolic acids, the flavonoids catechin, and quercetin were recorded in significant concentration in EA extract, where catechin was the most dominant $\left(8144.98 \mu \mathrm{g} \mathrm{g}^{-1}\right)$. The catechin was also determined in $\mathrm{MeOH}$ and $\mathrm{EtOH}$ extract, but in a much lower value $\left(704.55 \mu \mathrm{g}\right.$; $\left.396.16 \mu \mathrm{g} \mathrm{g}^{-1}\right)$ than in EA extract. Quercetin was found in significant quantity only in the EA extract $\left(4541.70 \mu \mathrm{g} \mathrm{g}^{-1}\right)$. A plenty of studies supported various health benefits. This phenolic compound is reputable as one of the most powerful antioxidant, ${ }^{31,32}$ while several studies have shown the a strong connection between catechin and inhibition of cancerogenesis, such like suppression on breast and ovarian cancer cell growth. ${ }^{33,34}$ Flavonoid glucosides were identified in all tested extracts, and generally their concentration were the most abundant in EA extract. The highest concentration of luteolin-7-O- $\beta$-glucoside was found in the EtOH $\left(1186.34 \mu \mathrm{g} \mathrm{g}^{-1}\right)$ and $\mathrm{MeOH}\left(903.94 \mu \mathrm{g} \mathrm{g}^{-1}\right)$ extracts and apigenin-7-O- $\beta$-glucoside was detected in much lower concentration in all extracts. Further, kaempherol-3-O-glucoside and quercitrin-hexosides were noticed in ET extract in plentiful amount $\left(1038.52 \mu \mathrm{g} \mathrm{g}^{-1} ; 2274.85 \mu \mathrm{g} \mathrm{g}^{-1}\right)$. Due to the fact that the information related to phenol profile of this plant is very scattered and that there are no reports for A. vulgaris from this region (locality), the results obtained in this study represent a significant contribution to ethnobotany and phytomedicine.

\section{Total phenolic content and antioxidant activity}

The results presented in Table 2 have shown the means of the total phenolics content and antioxidant activity of $A$. vulgaris extracts using several in vitro assays. The total phenolic content were strongly correlated with antioxidant activity, whereas the EA extract showed the highest content of total phenol compounds (9.65 mg GAE per g) of extract and therefore the highest antioxidant activity.

Uniformly, it can be concluded that the EA extract demonstrated the highest antioxidant potential, where the most pronounced and significant antioxidant effect of tested extracts was observed for DPPH and FRAP assays (DPPH: $502.56 \mathrm{mg}$ TE per $\mathrm{g}$ extract; FRAP: $8745.31 \mathrm{mg}$ EAA per $\mathrm{g}$ of dry extract), followed by $\mathrm{MeOH}$ extract. The $\mathrm{H}_{2} \mathrm{O}$ extract has shown significantly low anti-radical activity compared to the other extracts. It is not unusual for antioxidant assays to be less sensitive and accurate to some bioactive compounds that are presented in the testes 
Table 2 Evaluation of antioxidant potential and total phenolic content ${ }^{a}$

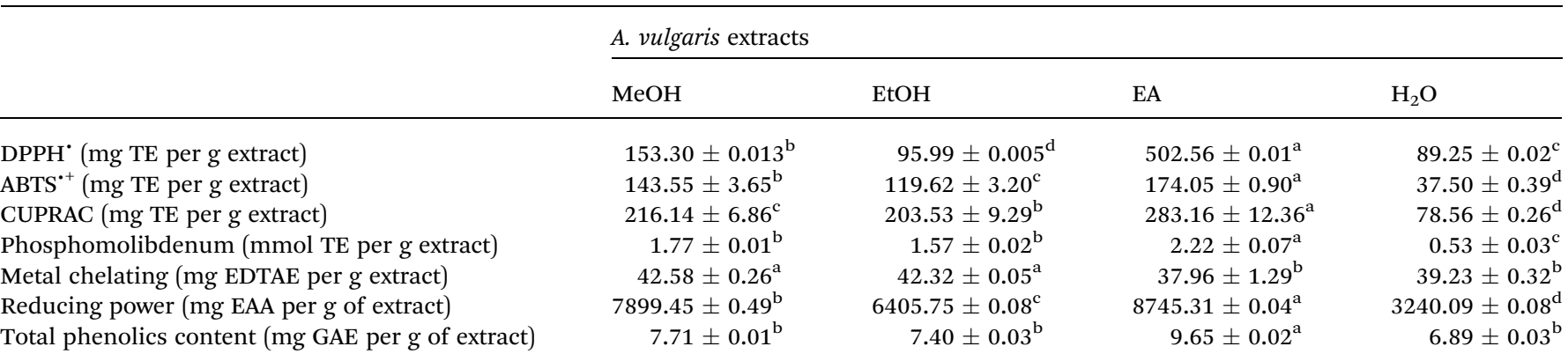

${ }^{a}$ Values expressed are means \pm S.D. of three parallel measurements; a-d means in the same row not sharing the same superscript are significantly different $(p<0.05)$; TE: trolox equivalent; EDTAE: EDTA equivalent; GAE: gallic acid equivalent.

samples. Therefore, more than two assays should be used in order to obtain more completed results of antioxidant effect. ${ }^{35}$ Using DPPH, $\mathrm{ABTS}^{\cdot+}$ and ${ }^{\circ} \mathrm{OH}$ assays, Boroja et al., 2018 have demonstrated a great antioxidant potential of the Lady's mantle methanol extract which has been higher than synthetic antioxidant. ${ }^{4}$

\section{Enzyme inhibitory effects of the A. vulgaris extracts}

To determine enzyme inhibitory effects of A. vulgaris extracts, cholinesterases, tyrosinase and amylase were selected as target enzymes. The results are presented in Table 3. The highest AChE inhibition was provided by EA extract (5.21 mg GALAE per g) and other extracts had almost similar inhibitory effects on the enzyme. The activity for EA may be linked with the higher level of phenolics and this approach was supported by several researchers, who reported the positive correlation between phenolic level and AChE inhibition. ${ }^{27,36}$ However, the BChE inhibition effects can be ranked as $\mathrm{H}_{2} \mathrm{O}>\mathrm{EtOH}>\mathrm{EA}>\mathrm{MeOH}$. The observed BChE inhibitor effect for $\mathrm{H}_{2} \mathrm{O}$ can be attributed to non-phenolic inhibitors ${ }^{37}$ since the water extract, as expected, exhibited the lowest phenolic level (see Table 2). Regarding tyrosinase inhibitory effects, the best activity was observed for MeOH (79.84 mg KAE per g), followed by EtOH, EA and $\mathrm{H}_{2} \mathrm{O}$. These findings for tyrosinase inhibitory effects might be connected with the of phenolics that are presented in the tested extracts, including apigenin-7-O- $\beta$-glucoside, luteolin-7-O- $\beta$ glucoside, quercetin and rutin, which have been already reported anti-tyrosinase agents. ${ }^{38-40}$ High anti-tyrosinase and anti-cholinesterase activity of $A$. vulgaris ethanolic extracts have been reported. ${ }^{42}$ The EA extract ( 0.41 mmol ACAE per g) showed the most effective amylase inhibitor effect, while the weakest inhibitory effect was found in the $\mathrm{H}_{2} \mathrm{O}$ extract. Some phenolics, such as catechin, quercetin and luteolin-7-O- $\beta$-glucoside, could be responsible for the observed amylase inhibitory result of EA. In accordance with our findings, these phenolics exhibited significant anti-amylase abilities. ${ }^{42-44}$ To sum up, A. vulgaris could be suggested as valuable sources of natural enzyme inhibitors to combat major health problems such as diabetes and skin related disorders, as already reported in

Table $4 \quad I_{50}$ values of effect Alchemilla vulgaris extracts in cytotoxicity

\begin{tabular}{llllll}
\hline \multirow{2}{*}{ Cell line } & Assay & MeOH & EtOH & EA & $\mathrm{H}_{20}(\mu \mathrm{g} \mathrm{mL}$ \\
\cline { 3 - 6 } A2780 & MTT & $27.9 \pm 1.9$ & $40.3 \pm 0.4$ & $43.3 \pm 0.9$ & $67 \pm 2.4$ \\
& CV & $38.3 \pm 1.1$ & $43.9 \pm 0.1$ & $42.6 \pm 1.3$ & $78.4 \pm 1.9$ \\
HeLa & MTT & $80.6 \pm 6.3$ & $84.75 \pm 5$ & $46.4 \pm 5.1$ & $>100$ \\
& CV & $>100$ & $>100$ & $53.8 \pm 3.9$ & $>100$ \\
MCF7 & MTT & $41.9 \pm 0.6$ & $58.7 \pm 1.6$ & $31.3 \pm 1.5$ & $94.1 \pm 1.2$ \\
& CV & $47.2 \pm 0.4$ & $64.4 \pm 0.1$ & $37.5 \pm 5$ & $95 \pm 7.1$ \\
PC-3 & MTT & $54.4 \pm 2.5$ & $43.5 \pm 1.1$ & $18.7 \pm 0.9$ & $>100$ \\
& CV & $73.5 \pm 4.2$ & $61.1 \pm 4.7$ & $31.7 \pm 0.3$ & $>100$
\end{tabular}

Table 3 Enzyme inhibitory effects of Alchemilla vulgaris extracts ${ }^{a}$

$$
\text { A. vulgaris extracts }
$$

\begin{tabular}{|c|c|c|c|c|}
\hline Enzyme inhibition assays & $\mathrm{MeOH}$ & $\mathrm{EtOH}$ & EA & $\mathrm{H}_{2} \mathrm{O}$ \\
\hline BChE inhibition (mg GALAE per g extract) & $9.59 \pm 0.14^{\mathrm{a}}$ & $9.71 \pm 0.09^{\mathrm{a}}$ & $9.61 \pm 0.02^{\mathrm{a}}$ & $10.19 \pm 0.16^{\mathrm{a}}$ \\
\hline Amylase inhibition (mmol ACAE per g extract) & $0.34 \pm 0.04^{\mathrm{a}}$ & $0.32 \pm 0.03^{\mathrm{a}}$ & $0.41 \pm 0.03^{\mathrm{a}}$ & $0.22 \pm 0.03^{\mathrm{b}}$ \\
\hline
\end{tabular}

${ }^{a}$ Values expressed are means \pm S.D. of three parallel measurements. In each row different letters mean significant differences $(p<0.05)$; GALAE: galatamine equivalent; KAE: kojic acid equivalent; ACAE: acarbose equivalent. 
ethnobotanical notes for the Balkan region ${ }^{\mathbf{1 5}}$ and as a novel report presented in our current study - for treating the neurodegenerative disorders, including Alzheimer and Parkinson's disease.

\section{Anticancer activity of $\boldsymbol{A}$. vulgaris extracts using different cancer cell lines}

To evaluate the impact of isolated extracts on tumor cell growth, human breast MCF7, ovarian A2780, cervical HeLa and prostate cancer PC-3 cell lines were used. All selected cell lines were isolated from tumors developed in tissues regulated by hormones and accordingly, highly sensitive to hormonal status.
During tumor progression, some of them like A2780, HeLa and PC-3 lost their hormone receptors and became independent to the treatment with hormone antagonist. ${ }^{45-48}$ This qualified them as invasive and, in general, resistant to conventional chemotherapeutics. Having all this in mind, it was intriguing to assess sensitivity of hormone-dependent (MCF-7) as well as independent cell lines (A2780, HeLa, PC-3) to different extracts of $A$. vulgaris, whose composition varied dependingon the type of the solvent used in extraction procedure. Cells were cultivated with isolated extracts for $72 \mathrm{~h}$ when the number of viable cells in the culture was assessed by MTT and CV tests. As presented in Table 4 and Fig. $1, \mathrm{H}_{2} \mathrm{O}$ extract was almost inefficient
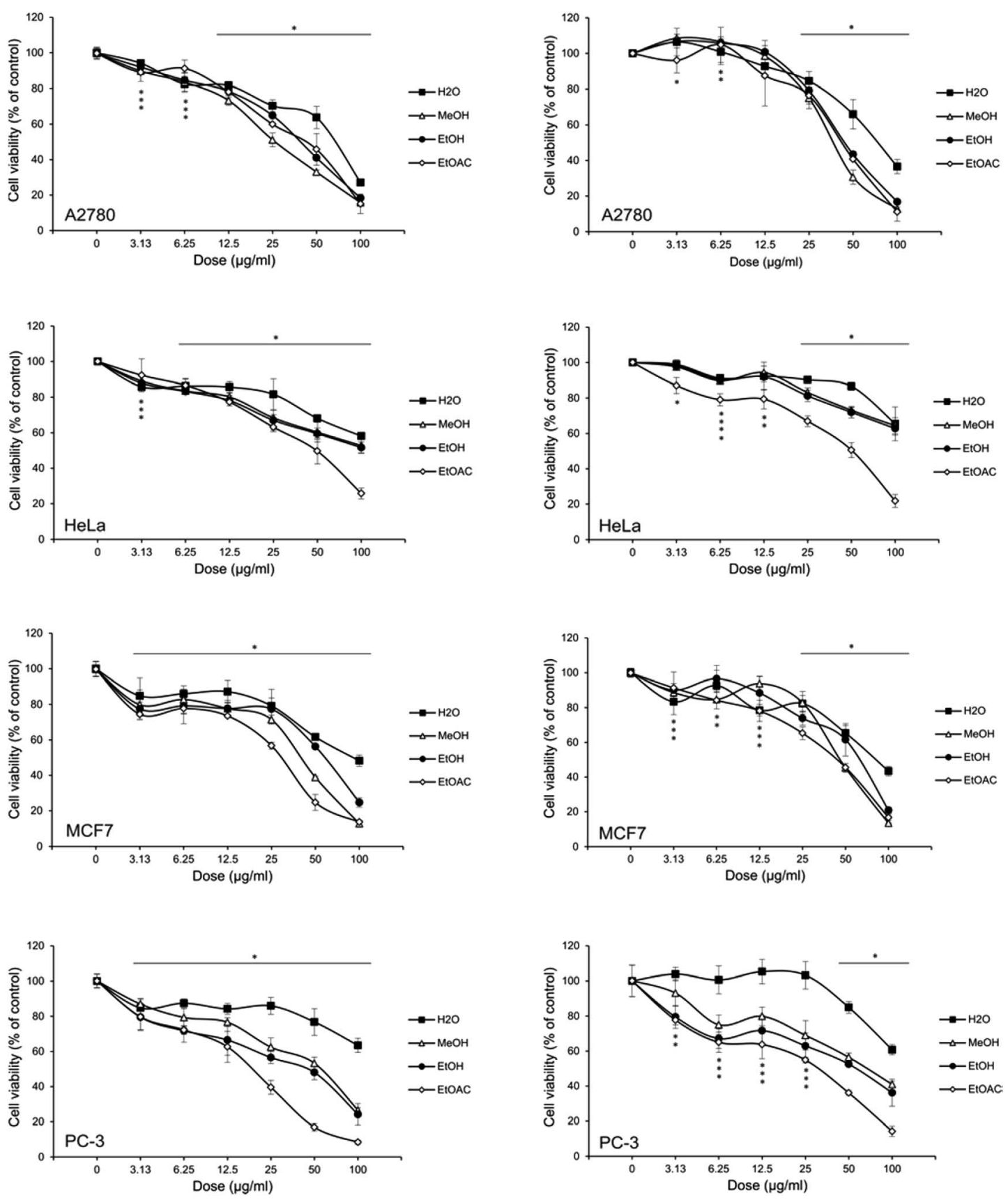

Fig. 1 Effect of Alchemilla vulgaris extracts on different tumor cell lines. 
in tumor cell growth suppression. Three other extracts displayed the different potential to decrease the number of viable cells depending on the cell type. In general, despite different origin and sensitivity to hormone stimulation of tested cell lines the strongest potential to decrease tumor cells' viability possessed EA extract. While cervical adenocarcinoma HeLa was almost insensitive to $\mathrm{MeOH}$ and $\mathrm{EtOH}$, ovarian A2780 and breast carcinoma MCF7 displayed better response to treatment with $\mathrm{MeOH}$ than $\mathrm{EtOH}$ extract. To evaluate the selectivity toward malignant phenotype, peritoneal exudates cells isolated from C57BL6 mice were exposed to the same range of doses as those used for evaluation of the cytotoxicity against malignant cells. Differently, to tested cancer cell lines, $\mathrm{MeOH}$ and EtOH extracts were not able to reduce the viability of normal cells for $50 \%$. Since $\mathrm{IC}_{50}$ value was not reached upon the treatment with indicating extracts, it can be concluded that the intested range of doses they are non-toxic for normal phenotype and therefore, selective to malignant cells. Differently, to them, $\mathrm{IC}_{50}$ value for EA was determined at $100 \mu \mathrm{g} \mathrm{mL}^{-1}$ but, regarding to high sensitivity of all tested lines to this extract, selectivity index varies from 2-3, depending on the type of tumor cells. Taking together, apart from its confirmed antioxidant and antiinflammatory action, A. vulgaris extracts might directly impact the growth of malignant cells. Especial importance represents the fact the even hormone independent cell lines originating from tumors known as highly aggressive and nonresponsive to conventional therapy ${ }^{\mathbf{4 9}}$ were sensitive to tested extracts. Despite to ethno-botanical data showing the anticancer potential of $A$. vulgaris against female reproductive tissues we might speculate that male reproductive cancers, like in this case prostate cancer, ${ }^{50}$ or other type of tumors can be targeted with this plant constituents. Varying in efficacy of used A. vulgaris extract against tested cell lines might be ascribed to the differences in content, concentration and ratio of biologically active compounds with proven anticancer activity. Namely, it is well recognized that both caffeic and gallic acid, that are present in EA extract, possess strong anti-proliferative and cytotoxic properties in wide range of tumor types such as those used in this study (breast, cervical, ovarian, prostate carcinoma). ${ }^{51-53}$ These phenolic acids affected main signaling pathways involved in cell cycle progression and cell death. Moreover, they interfered with migrative and invasive properties, epithelial/ mesenchimal transition and even angiogenesis. Very important property of mentioned phenolic compounds is their ability to sensitize tumor cells to conventional therapeutics or even to affect cells initially resistant to chemotherapy. ${ }^{53}$ In addition, ${ }^{54}$ genistein, protein tyrosine kinase inhibitor, and quercetin, present in EA extract only, displayed strong anticancer potential realized preferentially through inhibition of cell cycle progression, induction of apoptosis ${ }^{55}$ affecting MAP-ERK signaling pathway, inhibition of metastatic properties of malignant cells etc. The anticancer properties of these molecules were even proved in several in vivo tumor models. ${ }^{56}$ Concordantly, with described data these isoflavones might sensitize malignant cells to conventional therapies. Since quercetin inhibited stem cell proliferation, ${ }^{56}$ its presence might be highly beneficial in terms of treatment of aggressive malignant tumors. The rest of active compounds for example, catechin, are also compounds with potential to limit tumor cell growth. ${ }^{57}$ Apart from discussed antitumor properties, catechin modulated epigenetic events such as DNA methylation and demethylation, as well as acetylation deacetylation of histones, influence tubulin-microtubule $^{58,59}$ equilibrium and changed the expression of enzymes relevant for migration and invasion of malignant cells. Plenty of literature data confirmed that efficacy of any herbal extract is defined by the mixture and interplay of its constituents. Despite the lack of scientific data about the anticancer features of $A$. vulgaris the panel of biologically active substances inside of it indicated its enormous potential in the field of anticancer therapy and needs of further evaluation.

\section{Conclusion}

Alchemilla vulgaris is a generally poorly studied plant, apart from its long and known traditional use world while. The results obtained by the phytochemical examination and the assessment of the biological activities of $A$. vulgaris extracts, indicated the justification of use of the plant in traditional medicine, mainly for woman related diseases due to hormone dependent anticancer activity (breast and ovarian anticancer effects), as well as amylase and tyrosinase inhibitory effects, which might be related to antidiabetic and skin-related diseases, as previously reported for Lady's mantle of the Balkans region. Moreover, potential use in prevention of neuro-degenerative illnesses was shown by inhibitory effects on cholinesterases. Great biological activity of $A$. vulgaris. extracts is linked with its phenolic profile, rich in catechin, quercetin and its hexoside, luteolin, apigenin, gallic and caffeic acids. Our results present a first report on anticancer activity of hormone dependent cancer lines, for this plant. The ethylacetate extract should be emphasized due its exceptional antioxidant, enzyme inhibitory and antitumor activity upon the content of the phenolic compounds such as catechin, quercetin and phenolic acids. Further research will be focused on mechanisms of anticancer activity and modes of action of the key most efficient plant metabolites. Overall this Alchemilla vulgaris from Vlasina lake (central Balkan) is a promising a valuable source of different bioactive compounds that could have great health benefits.

\section{Conflicts of interest}

The authors declare there is no conflict of interest.

\section{Acknowledgements}

This work was supported by the Ministry of Education, Science and Technological Development of the Republic of Serbia [grant numbers 172058 and 173013].

\section{References}

$1 \mathrm{~S}$. Tasic, Ethnobotany in see-wb countries; traditional uses of indigenous plants, 2012, vol. 10, pp. 71-81. 
2 K. Ghedira, P. Goetz and R. L. Jeune, Alchemilla vulgaris, Phytothérapie, 2012, 263-266.

3 Y. Kiselova, D. Ivanova, T. Chervenkov, D. Gerova and B. Galunska, Correlation between the In Vitro Antioxidant Activity and Polyphenol Content of Aqueous Extracts from Bulgarian Herbs, Phytother. Res., 2006, 965, 961-965.

4 T. Boroja, V. Mihailovi, J. Katani, S. Pan, S. Nikles, P. Imbimbo, et al., The biological activities of roots and aerial parts of Alchemilla vulgaris L, S. Afr. J. Bot., 2018, 116, 175-184.

5 S. Takir, I. Altun, B. Sezgi, S. Suzgec-Selcuk, A. Mat and B. Uydes-Dogan, Vasorelaxant and blood pressure lowering effects of alchemilla vulgaris: A comparative study of methanol and aqueous extracts, Pharmacogn. Mag., 2015, 11(41), 163, http:/www.phcog.com/text.asp?2015/11/41/163/ 149733.

6 E. I. Filippova, Antiviral Activity of Lady' s Mantle (Alchemilla vulgaris L.) Extracts against Orthopoxviruses, Bull. Exp. Biol. Med., 2017, 163(3), 374-377.

7 O. Bahadir, I. Keskin and N. Ipek, Science Direct Evaluation of hepatoprotective and antidiabetic activity of Alchemilla mollis, Biomed. Pharmacother., 2017, 86, 172-176.

8 S. Ivancheva, M. Nikolova and R. Tsvetkova, Pharmacological activities and biologically active compounds of Bulgarian medicinal plants, Phytochemistry: Advances in Research, 2006, vol. 37661, pp. 87-103, http://www.medpharmsofia.eu/files/DIR4/Bulgarian-medicinal-plants.pdf.

9 N. O'Flynn, Menstrual symptoms: The importance of social factors in women's experiences, Br J Gen Pract., 2006, 56(533), 950-957.

10 B. Saad, H. Azaizeh, G. Abu-Hijleh and O. Said, Safety of Traditional Arab Herbal Medicine, J. Evidence-Based Complementary Altern. Med., 2006, 3(4), 433-439.

11 M. Ma, L. Djurdjevi, M. Mitrovi, O. Kosti, B. Karad and P. Pavlovi, An ethnobotanical survey of traditionally used plants on Suva planina mountain (south-eastern Serbia), J. Ethnopharmacol., 2015, 175, 93-108.

12 J. Zivkovic, C. Nada and M. Terě, Ethnobotanical study on traditional use of medicinal plants in South-Western Serbia, Zlatibor District, 2013.

13 K. Šavikin, G. Zdunić, N. Menković, J. Živković, N. Ćujić, M. Tereščenko, et al., Ethnobotanical study on traditional use of medicinal plants in South-Western Serbia, Zlatibor district, J. Ethnopharmacol., 2013, 146(3), 803-810.

14 E. Neagu, G. Paun, C. Albu and G. Radu, Antioxidant activity of Alchemilla vulgaris and Filipendula ulmaria extracts, J. Taiwan Inst. Chem. Eng., 2015, 1-6, DOI: 10.1016/j.jtice.2015.01.026.

15 M. Tasić-Kostov, I. Arsić, D. Pavlović, S. Stojanović, S. Najman, S. Naumović, et al., Towards a modern approach to traditional use: in vitro and in vivo evaluation of Alchemilla vulgaris L. gel wound healing potential, J. Ethnopharmacol., 2019, 238, DOI: 10.1016/j.jep.2019.03.016.

16 J. Choi, Y. Park, M. Yun and J. Seol, Biomedicine \& Pharmacotherapy E ff ect of herbal mixture composed of Alchemilla vulgaris and Mimosa on wound healing process, Biomed. Pharmacother., 2018, 106, 326-332, DOI: 10.1016/j.biopha.2018.06.141.
17 S. Akbulut and M. M. Bayramoglu, Studies on EthnoMedicine Reflections of Socio-economic and Demographic Structure of Urban and Rural on the Use of Medicinal and Aromatic Plants: The Sample of Trabzon Province, Studies on Ethno-Medicine, 2017, 5070.

18 D. Orčić, M. Francišković, K. Bekvalac, E. Svirčev, I. Beara, M. Lesjak, et al., Quantitative determination of plant phenolics in Urtica dioica extracts by high-performance liquid chromatography coupled with tandem mass spectrometric detection, Food Chem., 2014, 143, 48-53, http://www.ncbi.nlm.nih.gov/pubmed/24054211.

19 J. C. Espin, C. Soler-rivas and H. J. Wichers, Characterization of the Total Free Radical Scavenger Capacity of Vegetable Oils and Oil Fractions Using 2,2-Diphenyl-1-picrylhydrazyl Radical, J. Agric. Food Chem., 2000, 648-656.

20 P. Prieto, M. Pineda and M. Aguilar, Spectrophotometric Quantitation of Antioxidant Capacity through the Formation of a Phosphomolybdenum Complex: Specific Application to the Determination of Vitamin E1, Anal. Biochem., 1999, 341, 337-341.

21 I. F. F. Benzie and J. J. Strain, The Ferric Reducing Ability of Plasma (FRAP) as a Measure of "Antioxidant Power": The FRAP Assay, Anal. Biochem., 1996, 76, 70-76.

22 A. Medina-Remón, A. Barrionuevo-González, R. Zamora-Ros, C. Andres-Lacueva, R. Estruch, M.-A. Martínez-González, et al., Rapid Folin-Ciocalteu method using microtiter 96well plate cartridges for solid phase extraction to assess urinary total phenolic compounds, as a biomarker of total polyphenols intake, Anal. Chim. Acta, 2009, 634(1), 54-60.

23 S. Uysal, G. Zengin, M. Locatelli, M. B. Bahadori and A. Aktumsek, Cytotoxic and Enzyme Inhibitory Potential of Two Potentilla species (P. speciosa L. and P. reptans Willd), Phytomedicine, 2017, 8, 1-11.

24 G. Zengin, M. Locatelli, A. Stefanucci, G. Macedonio, E. Novellino, S. Mirzaie, et al., Chemical characterization, antioxidant properties, anti-inflammatory activity, and enzyme inhibition of Ipomoea batatas L. leaf extracts, Int. J. Food Prop., 2017, 20(2), 1907-1919.

25 E. J. Llorent-Martínez, G. Zengin, M. L. F. de Córdova, O. Bender, A. Atalay, R. Ceylan, et al., Traditionally used lathyrus species: Phytochemical composition, antioxidant activity, enzyme inhibitory properties, cytotoxic effects, and In Silico studies of L. Czeczottianus and L. Nissolia, Front. Pharmacol., 2017, 8, 1-20.

26 A. Mollica, G. Zengin, M. Locatelli, A. Stefanucci, G. Macedonio, G. Bellagamba, et al., An assessment of the nutraceutical potential of Juglans regia L. leaf powder in diabetic rats, Food Chem. Toxicol., 2017, 107, 554-564.

27 A. Mocan, G. Zengin, A. Mollica, A. Uysal, E. Gunes, G. Cri, et al., Biological effects and chemical characterization of Iris schachtii Markgr. extracts: A new source of bioactive constituents, Food Chem. Toxicol., 2017, 112, 448-457.

28 K. E. Heim, A. R. Tagliaferro and D. J. Bobilya, Flavonoid antioxidants: chemistry, metabolism and structure-activity relationships, J. Nutr. Biochem., 2002, 13, 572-584.

29 N. Tajik, M. Tajik, I. Mack and P. Enck, The potential effects of chlorogenic acid, the main phenolic components in 
coffee, on health: a comprehensive review of the literature, Eur. J. Nutr., 2017, 56(7), 2215-2244.

30 P. Taylor, An Outlook on Chlorogenic Acids - Occurrence, Chemistry, Technology, and Biological Activities, 2013, pp. 3741.

31 S. M. Duckstein, E. M. Lotter, U. Meyer and U. Lindequist, Phenolic Constituents from Alchemilla vulgaris L. and Alchemilla mollis (Buser) Rothm. at Different Dates of Harvest, Z. Naturforsch., C: J. Biosci., 2012, 67(11-12), 529540.

32 Y. Li, J. Yao, C. Han, J. Yang, M. T. Chaudhry, S. Wang, et al., Quercetin, Inflammation and Immunity, Nutrients, 2016, 8(3), 167.

33 L. Xiang, A. Wang, J. Ye, X. Zheng, C. A. Polito, J. Lu, et al., Suppressive Effects of Tea Catechins on Breast Cancer, Nutrients, 2016, 8(8), 458.

34 C. S. Yang and H. Wang, Mechanistic issues concerning cancer prevention by tea catechins, Mol. Nutr. Food Res., 2011, 819-831.

35 S. B. Kedare and R. P. Singh, Genesis and development of DPPH method of antioxidant assay, J. Food Sci. Technol., 2011, 48, 412-422.

36 D. Szwajgier, Anticholinesterase activity of selected phenolic acids and flavonoids - interaction testing in model solutions, Ann. Agric. Environ. Med., 2015, 22(4), 690-694.

37 E. L. Konrath, S. Passos, L. C. Klein-júnior and A. T. Henriques, Alkaloids as a source of potential anticholinesterase inhibitors for the treatment of Alzheimer's disease, J. Pharm. Pharmacol., 2013, 1-25.

38 Y. Kim and H. Uyama, Tyrosinase inhibitors from natural and synthetic sources: structure, inhibition mechanism and perspective, Cell. Mol. Life Sci., 2005, 62, 1707-1723.

39 S. Y. Lee, N. Baek and T. Nam, Natural, semisynthetic and synthetic tyrosinase inhibitors, J. Enzyme Inhib. Med. Chem., 2015, 1-13.

40 Y. Si, S. Yin, S. Oh, Z. Wang, S. Ye, et al., An Integrated Study of Tyrosinase Inhibition by Rutin: Progress using a Computational Simulation An Integrated Study of Tyrosinase Inhibition by Rutin: Progress using a Computational Simulation, J. Biomol. Struct. Dyn., 2015, 37-41.

41 E. Neagu, G. Paun, C. Albu and G. Radu, Assessment of acetylcholinesterase and tyrosinase inhibitory and antioxidant activity of Alchemilla vulgaris and Filipendula ulmaria extracts, J. Taiwan Inst. Chem. Eng., 2015, 52, 1-6, DOI: 10.1016/j.jtice.2015.01.026.

42 M. Yilmazer-musa, A. J. Michels, E. Schneider and B. Frei, Grape seed and tea extracts and catechin 3-gallates are potent inhibitors of $\alpha$-amylase and $\alpha$-glucosidase activity, $J$. Agric. Food Chem., 2012, 60(36), 8924-8929.

43 C. Jhong and Y. Chia, Screening alpha-glucosidase and alpha-amylase inhibitors from natural compounds by molecular docking in silico, International Union of Biochemistry and Molecular Biology, 2015, 242-251.

44 A. I. Martinez-Gonzalez, Á. G. Díaz-Sánchez, A. de la Rosa, I. Bustos-Jaimes and E. Alvarez-Parrilla, Inhibition of $\alpha$ - amylase by flavonoids: Structure-activity relationship (SAR), Spectrochim. Acta, Part A, 2019, 206, 437-447.

45 L. Campbell, J. Gee, K. M. Taylor, R. I. Nicholson, M. Gumbleton and Á. Ráháeáerk, Growth of hormonedependent MCF-7 breast cancer cells is promoted by constitutive caveolin-1 whose expression is lost in an EGFR-mediated manner during development of tamoxifen resistance, Breast Cancer Res. Treat., 2010, 575-591.

46 S. Tai, Y. Sun, J. M. Squires, H. Zhang, W. K. Oh, C. Liang, et al., PC3 Is a Cell Line Characteristic of Prostatic Small Cell Carcinoma, Nutr. Cancer, 2011, 1679, 1668-1679.

47 M. Maggiolini, G. Statti, A. Vivacqua, S. Gabriele, V. Rago, M. Loizzo, et al., Estrogenic and antiproliferative activities of isoliquiritigenin in MCF7 breast cancer cells, J. Steroid Biochem. Mol. Biol., 2002, 82, 315-322.

48 K. Brasseur, V. Leblanc, F. Fabi, S. Parent, C. Descôteaux, G. Bérubé, et al., ER-Targeted Therapy in Ovarian Cancer Cells by a Novel Estradiol-Platinum(II) Hybrid, Endocrinology, 2013, 154, 2281-2295.

49 R. Clarke, N. Brunner, B. S. Katzenellenbogent, E. W. Thompson, M. J. Normant, C. Koppit, et al., Progression of human breast cancer cells from hormonedependent to hormone-independent growth both in vitro and in vivo, Proc. Natl. Acad. Sci. U. S. A., 1989, 86, 3649-3653.

50 E. Heidarian, M. Keloushadi, K. Ghatreh-samani and P. Valipour, ScienceDirect signaling pathways and invasion activity by gallic acid in prostate cancer PC3 cells, Biomed. Pharmacother., 2016, 84, 264-269, DOI: 10.1016/ j.biopha.2016.09.046.

51 C. Gherman, O. L. Braicu and O. Zanoaga, Caffeic acid phenethyl ester activates pro-apoptotic and epithelial mesenchymal transition-related genes in ovarian cancer cells A2780 and A2780cis, Mol. Cell. Biochem., 2016, 413(1), 189-198.

52 J. Tai, S. Cheung, E. Chan and D. Hasman, Antiproliferation Effect of Commercially Brewed Coffees on Human Ovarian Cancer Cells In Vitro, Nutr. Cancer, 2010, 62, 1044-1057.

53 M. Tyszka-czochara, Caffeic Acid and Metformin Inhibit Invasive Phenotype Induced by TGF- $\beta 1$ in C-4I and HTB35/SiHa Human Cervical Squamous Carcinoma Cells by Acting on Different Molecular Targets, Int. J. Mol. Sci., 2018, 19(1), E266.

54 V. Ajdžanovi, B. Filipovi, D. Milji, S. Mijatovi, D. Maksimovi, M. Miler, et al., Review article: Prostate cancer metastasis and soy isoflavones: a dogfight over a bone, EXCLI Journal, 2019, 106-126.

55 M. Hashemzaei, A. D. Far, A. Yari, R. E. Heravi, K. Tabrizian, S. M. Taghdisi, et al., Anticancer and apoptosis - inducing effects of quercetin in vitro and in vivo, Oncol. Rep., 2017, 819-828.

56 S. Erdogan, K. Turkekul, I. Dibirdik, O. Doganlar, Z. B. Doganlar, A. Bilir, et al., Biomedicine \& Pharmacotherapy Midkine downregulation increases the e ffi cacy of quercetin on prostate cancer stem cell survival and migration through PI3K/AKT and MAPK/ERK pathway, Biomed. Pharmacother., 2018, 107, 793-805, DOI: 10.1016/j.biopha.2018.08.061.

57 L. Schröder, P. Marahrens, J. G. Koch, H. Heidegger, T. Vilsmeier, T. Phan-brehm, et al., Effects of green tea, 
matcha tea and their components epigallocatechin gallate and quercetin on MCF-7 and MDA-MB-231 breast carcinoma cells, Oncol. Rep., 2019, 2(9), 387-396.

58 S. Chakrabarty, A. Ganguli, A. Das, D. Nag and G. Chakrabarti, Chemico-Biological Interactions Epigallocatechin-3-gallate shows anti-proliferative activity in HeLa cells targeting tubulin-microtubule equilibrium, Chem.-Biol. Interact., 2015, 242, 380-389, DOI: 10.1016/j.cbi.2015.11.004.

59 V. Gianfredi, D. Nucci, S. Vannini, M. Villarini, V. Gianfredi, D. Nucci, et al., In vitro Biological Effects of Sulforaphane (SFN), Epigallocatechin-3-gallate (EGCG), and Curcumin on
Breast Cancer Cells: A Systematic Review of the Literature, Nutr. Cancer, 2017, 1-10, DOI: 10.1080/01635581.2017.1359322.

60 R. Apak, K. Guclu, M. Ozyurek, S. E. Karademir and E. Ercag, The cupric ion reducing antioxidant capacity and polyphenolic content of some herbal teas, Int. J. Food Sci. Nutr., 2006, 57, 292-304.

61 T. C. P. Dinis, V. M. C. Madeira and L. M. Almeida, Action of phenolic derivatives (acetaminophen, salicylate, and 5aminosalicylate) as inhibitors of membrane lipid-peroxidation and as peroxyl radical scavengers, Arch. Biochem. Biophys., 1994, 315, 161-169. 